\title{
Post cardiac injury syndrome successfully treated with medications: a report of two cases
}

\author{
Mu-Shiang Huang ${ }^{1+}$, Yan-Hua Su ${ }^{2 \dagger}$ and Ju-Yi Chen ${ }^{1 *}$ (i)
}

\begin{abstract}
Background: Post cardiac injury syndrome (PCIS) is induced by myocardial infarction or cardiac surgery, as well as minor insults to the heart such as percutaneous coronary intervention (PCI), or insertion of a pacing lead. PCIS is characterized by pericarditis after injury to the heart. The relatively low incidence makes differential diagnosis of PCIS after $\mathrm{PCl}$ or implantation of a pacemaker a challenge. This report describes two typical cases of PCIS.

Case presentation: The first patient presented with signs of progressive cardiac tamponade that occurred two weeks after implantation of a permanent pacemaker. Echocardiography confirmed the presence of a moderate amount of newly-formed pericardial effusion. The second patient underwent PCl for the right coronary artery. However, despite an uneventful procedure, the patient experienced dyspnea, tightness of chest and cold sweats, and bradycardia two hours after the procedure. Echocardiography findings, which showed a moderate amount of newlyformed pericardial effusion, suggested acute cardiac tamponade, and compromised hemodynamics. Both patients recovered with medication.
\end{abstract}

Conclusion: These cases illustrated that PCIS can occur after minor myocardial injury, and that the possibility of PCIS should be considered if there is a history of possible cardiac insult.

Keywords: Pericarditis, Injury syndrome, Pacemaker, Coronary intervention

\section{Background}

Dressler syndrome, also known as post cardiac injury syndrome (PCIS), is characterized by the development of pericarditis with or without pleural effusion, days to weeks after a myocardial infarction. In addition to myocardial infarction, PCIS has been shown to be induced by pericardiotomy and blunt trauma, as well as by minor insults to the heart, such as coronary intervention, insertion of pacemaker leads, or radiofrequency ablation [1-5]. However, since PCIS induced by insertion of a pacemaker or by coronary intervention is relatively uncommon, it is possible to miss this as an important

\footnotetext{
*Correspondence: juyi@mail.ncku.edu.tw

${ }^{\top} \mathrm{MS}$ Huang and YH Su have contributed equal

1 Division of Cardiology, Department of Internal Medicine, National Cheng Kung University Hospital, College of Medicine, National Cheng Kung University, 138 Sheng-Li Road, Tainan 704, Taiwan

Full list of author information is available at the end of the article
}

differential diagnosis. Here, we describe two typical cases of PCIS.

\section{Case presentation Illustrative Case \# 1}

A 78-year-old man diagnosed with sick sinus syndrome received a permanent pacemaker (DDDR-MRI Medtronic [ventricular lead (MEDTRONIC cistofix 5076-58 cm); atrial lead (MEDTRONIC cistofix 5076$52 \mathrm{~cm})]$ ). The procedure itself and the post-procedure screening were both uneventful. The wound was clean, and there was no evidence of pneumothorax or hemothorax on the chest X radiography (CXR). The patient was discharged on the second day after the procedure.

However, the patient complained of a productive cough during a routine outpatient clinic follow-up visit conducted a week after the procedure. Laboratory findings showed a decrease in hemoglobin level from 10.9

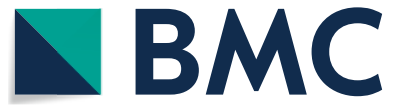

(c) The Author(s) 2021. Open Access This article is licensed under a Creative Commons Attribution 4.0 International License, which permits use, sharing, adaptation, distribution and reproduction in any medium or format, as long as you give appropriate credit to the original author(s) and the source, provide a link to the Creative Commons licence, and indicate if changes were made. The images or other third party material in this article are included in the article's Creative Commons licence, unless indicated otherwise in a credit line to the material. If material is not included in the article's Creative Commons licence and your intended use is not permitted by statutory regulation or exceeds the permitted use, you will need to obtain permission directly from the copyright holder. To view a copy of this licence, visit http://creativecommons.org/licenses/by/4.0/. The Creative Commons Public Domain Dedication waiver (http://creativeco mmons.org/publicdomain/zero/1.0/) applies to the data made available in this article, unless otherwise stated in a credit line to the data. 
to $8.9 \mathrm{mg} / \mathrm{dL}$. A CXR revealed newly developed borderline cardiomegaly and bilateral blunting of the diaphragmatic angle. Pacemaker interrogation results showed normal threshold and impedance of both leads. An evaluation performed at fourteen days after the procedure showed evidence of orthopnea, dyspnea upon exertion, and a minor fever $\left(38{ }^{\circ} \mathrm{C}\right)$. Physical examination showed engorgement of the jugular vein, basal crackles over the bilateral lower lung fields, and pitting edema in both legs. Laboratory data revealed worsening anemia (decrease in hemoglobin level from 8.9 to $7.7 \mathrm{mg} / \mathrm{dL}$ ), high NT-proBNP (1610 pg/ml), and hyponatremia (Na: $115 \mathrm{meq} / \mathrm{L}$, Osmo: 267), but no leukocytosis or worsening of renal function. An echocardiography revealed moderate pericardial effusion (maximal thickness $1.5 \mathrm{~cm}$ ) without dynamic diastolic collapse of the right ventricle (RV).

The patient was treated for congestion, and administered a nitrate infusion. The patient also received empirical treatment with antibiotics since the lowgrade fever was suggestive of an infection. The workup for pleural effusion showed evidence of transudate, and culture results for microorganisms tested were negative, including common aerobic and anaerobic bacterium as well as mycobacterium tuberculosis. Based on concerns about lead migration or protrusioninduced hemopericardium, the patient was subjected to chest computed tomography (CT), and no protrusion was detected (Fig. 1). Additionally, the density of pericardial effusion was 20 Hounsfield unit (HU),
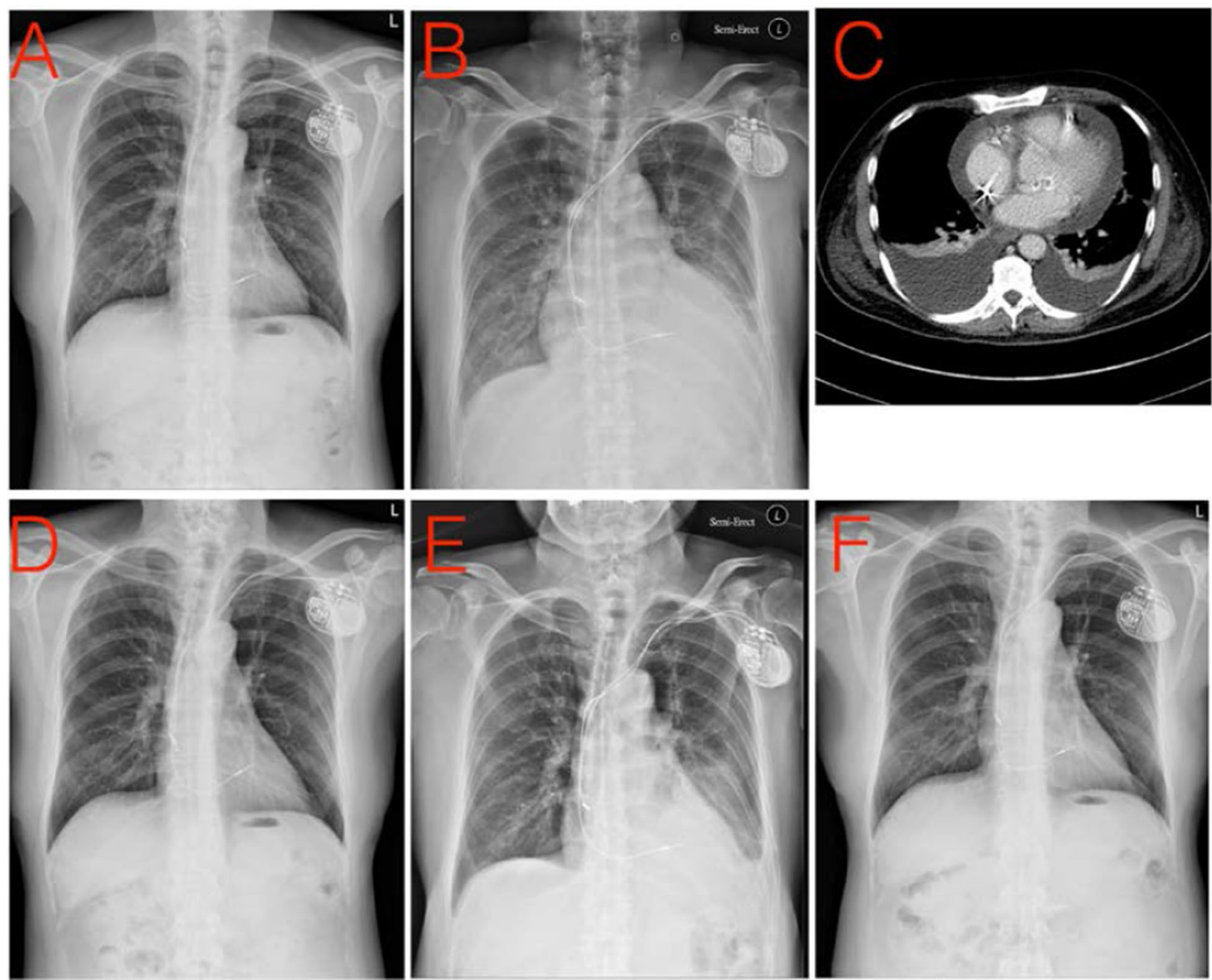

Fig. 1 Case 1 series images. a One day after implantation of pacemaker; $\mathbf{b}$ significant increase in cardiothoracic ratio at fourteen days after implantation; c CT scan showed no lead perforation, no pericardial effusion or pleural effusion; d After steroid treatment; e Recurrent PCIS, two weeks after completion of the steroid course; $\mathbf{f}$ Fourteen days after treatment with steroids and colchicine 
which also did not support the possibility of hemopericardium. There was a limited improvement in the patient's condition following several days of treatment, and echocardiography showed no worsening of pericardial effusion (thickness around $1.1 \mathrm{~cm}$ ). Based on a suspicion of PCIS, the patient was prescribed prednisolone (30 mg/day initially), after which there was a dramatic improvement of his condition. The dosage of prednisolone was gradually tapered off to $20 \mathrm{mg} /$ day after a week, $20 \mathrm{mg}$ to $10 \mathrm{mg} /$ day after two weeks, and the patient was maintained on $10 \mathrm{mg} /$ day for 8 weeks. Although the CXR returned to baseline after completion of the steroid treatment (Fig. 1), there was a recurrence of pleural effusion, leading to the resumption of low dose prednisolone treatment in addition to colchicine treatment. The patient recovered well after this treatment.

\section{Illustrative Case \#2}

An 82-year-old male with a history of chronic atrial fibrillation $\left(\mathrm{CHADS}_{2}: 3\right)$ was treated with rivaroxaban. The patient presented at the cardiology clinic with crescendo angina, and was reviewed with a coronary angiography examination, which showed significant focal stenosis at the orifice of the right coronary artery (RCA) (Fig. 2). The patient was subjected to percutaneous coronary intervention $(\mathrm{PCI})$, where a Xience Xpedition stent $(3.5 / 15 \mathrm{~mm})$ was deployed at the orifice. The procedure was uneventful, and the final angiogram showed good RCA flow, and no evidence of perforation, dissection, or extravasations (Fig. 2).

However, two hours after the procedure, the patient developed cold sweats, tightness in the chest, and hemodynamic compromise along with bradycardia (50 bpm) and hypotension (systolic blood pressure: $70-80 \mathrm{~mm}$ $\mathrm{Hg}$ ). Although a complete electrocardiography (ECG)

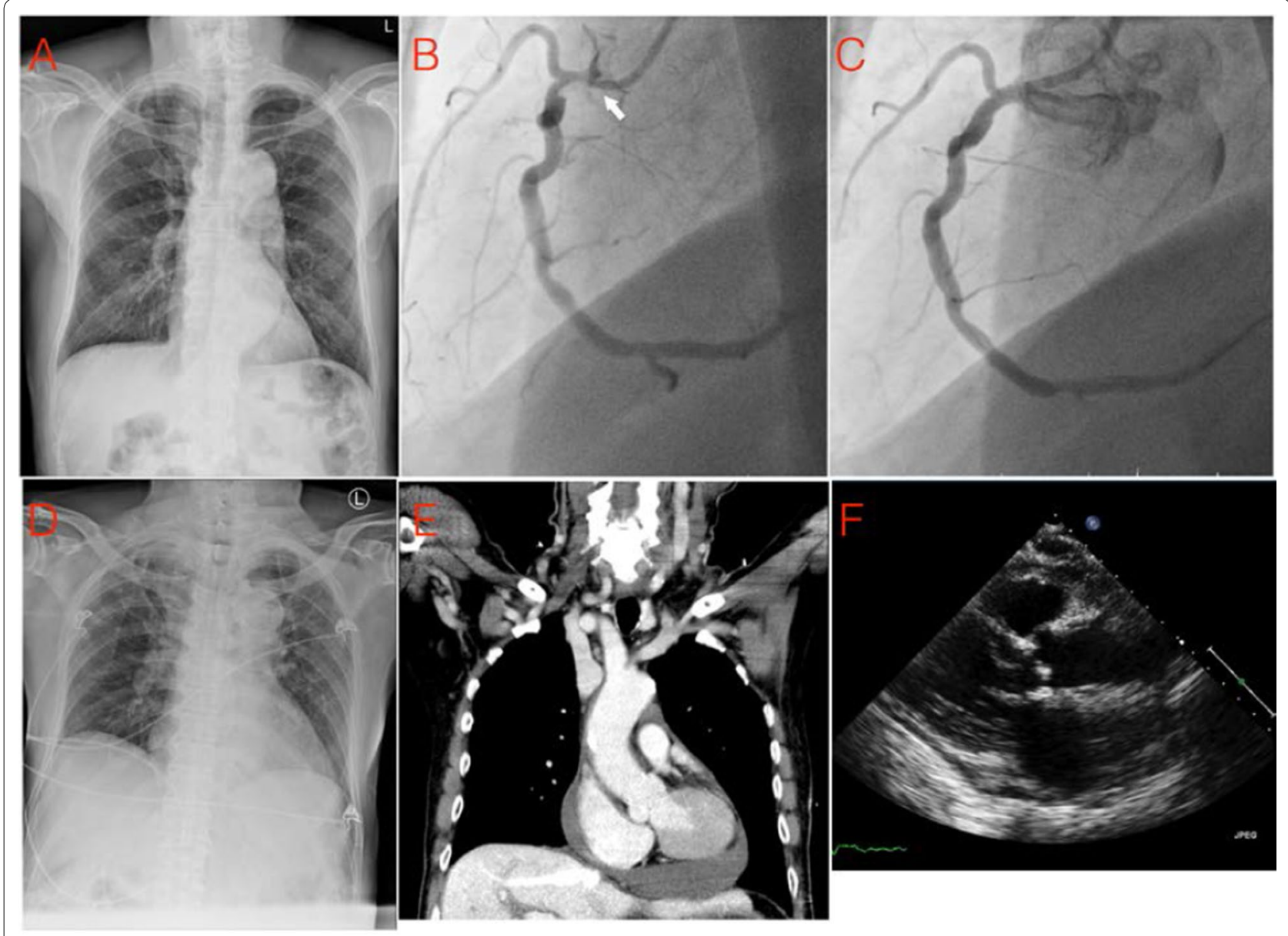

Fig. 2 Case 2 series images. a Normal chest radiography (CXR) before intervention; b White arrow: narrow portion of right coronary artery orifice; c Stent deployed at orifice, no extravasation found; $\mathbf{d}$ CXR at $2 \mathrm{~h}$ after stent deployment; e chest computed tomography (CT) showed no dissection, but a significant amount of pericardial effusion; f Follow-up echocardiography after steroid treatment showed decreased pericardial effusion without signs of RV collapse 
showed no abnormalities, echocardiography showed new pericardial effusion (thickness $1.1-1.5 \mathrm{~cm}$ ) with RV early diastolic collapse. This was immediately followed by a repeat coronary angiography, which showed good RCA flow without any extravasation, perforation or thrombosis. A chest CT scan with contrast showed no aortic dissection, and the density of pericardial effusion suggested hemopericardium (HU: 40) (Fig. 2). In addition to vasopressors which were administered to stabilize the hemodynamics, the patient was also prescribed a $50 \mathrm{mg}$ dose of hydrocortisone for PCIS. There was an improvement in the patient's condition on the second day and all vasopressors was discontinued in $18 \mathrm{~h}$. The patient was discharged to the outpatient department with a prescription for $20 \mathrm{mg}$ prednisolone, and remained stable at his follow-up visits. However, 9 months later, after we tapered off prednisolone, the patient had increased discomfort of dyspnea on exertion and the echocardiography showed pericardial effusion recurred. We prescribed colchicine and low dose prednisolone for its control and patient's discomfort improved.

\section{Discussion and conclusions}

PCIS is also known as pericarditis after pericardium injury. The incidence of PCIS in adults and children has been reported to be $10-40 \%$ after cardiac surgery $[1,2]$, about $1-5 \%$ after implantation of intra-cardiac devices $[1,3,4]$, and around $0.2 \%$ after coronary intervention [5]. Our cases were consistent with previous reports which showed that the onset of PCIS could vary from hours or days, and could occur up to 5-56 days after the procedure $[6,7]$. It is therefore crucial to recognize and diagnose PCIS while taking the patient's medical history, and the patient should be evaluated at regular follow-up visits for 1-3 months after the procedure [8].

Although the clinical manifestations of PCIS are nonspecific, there are several common indicators that should be closely monitored. Most patients present with fever (92\%), dyspnea (78\%), chest pain (50\%), elevation of C-reactive protein (CRP) or erythrocyte sedimentation rate (ESR) (80\%) and pleural effusion (61\%) [8]. Other findings include hyponatremia, unexplained anemia, or atrial fibrillation. Although pericardial effusion is observed in almost all PCIS patients, not all patients with pericardial effusion are symptomatic or require treatment. A recent study of 968 patients showed that when echocardiography was performed $24 \mathrm{~h}$ after implantation of a permanent pacemaker, 98 patients had some degree of pericardial effusion, while only 19 of the patients were symptomatic and 14 required an intervention. The remaining 79 patients remain asymptomatic and did not require treatment, and most of them were free of pericardial effusion after three months [9].
In our first patient, the cause of heart failure, pericardial effusion and pleural effusion was initially unknown, and device interrogation showed normal results. The patient had low-grade fever without leukocytosis. Blood culture and thoracocentesis were performed in order to rule out infection and the possibility of hemothorax. Although there was no progression of pericardial effusion or signs of tamponade on echocardiography, chest CT scan was performed to make sure there was no perforation of the pacing leads, or venous thrombosis by the leads. This procedure was similar to a previous study by Farbod et al. [8], where a diagnostic flow chart was designed to rule out infection, perforation, pulmonary embolism, and lead perforation before diagnosing PCIS caused by implantation of a cardiac device.

Our second patient showed acute pericardial effusion with unstable vital signs. However, there was no direct clinical evidence which could indicate the cause of pericardial effusion. Coronary angiography and chest CT scan were repeated immediately in order to exclude all possible causes of pericardial effusion, including coronary perforation, aortic dissection, or ventricle perforation. It has been reported that patients with stable hemodynamics who have pericardial effusion can be managed conservatively and tried in patients in whom ECG, cardiac enzyme levels, and inflammatory markers indicate typical pericarditis $[10,11]$. The following course of pericardial effusion recurrence 9 months later also supported PCIS etiology, rather than micro-perforation alone.

In our patients, hypervolemic hyponatremia was treated by diuresis, water restriction and increased salt intake. The three possible mechanisms which are thought to cause hyponatremia in PCIS include (1) increased secretion of ADH [12, 13], (2) elevation of atrial natriuretic factor [12], and (3) decreased effective volumes due to pericardial effusion which further decrease the glomerulus filtration rate [14]. Despite these different mechanisms, sodium levels can be corrected by simply treating the PCIS, and relieving the pericardial effusion has been shown to be sufficient to improve sodium levels without any other therapy $[12,14]$.

A number of studies have investigated risk factors for PCIS after pacemaker implantation. A study of 4280 patients who underwent pacemaker implantation reported that patients with a temporary transvenous pacemaker or steroid use within 7 days prior to implantation were more likely to have PCIS [15]. In addition, there was a higher risk of PCIS with active fixation in the right atrium (RA) (lateral, anterolateral side, or appendage) [9, 16]. A study of 1021 pacemaker implantations showed that there were no reports of PCIS after passive fixation or active fixation in the ventricle [17]. Female gender 
and antiplatelet therapy were also considered as risk factors for PCIS after pacemaker implantation [9]. In contrast, the risk factors of PCI-induced PCIS remain poorly understood, probably due to the low incidence rate.

The pathophysiology of PCIS remains unclear, and several studies suggested that it is an autoimmune reaction related to anti-myocardial antibodies resulting from injury to the myocardium or pericardium [1]. The autoimmune nature of PCIS is supported by clinical features such as the latent period between the insult and symptoms, elevation of inflammatory markers, good response to NSAIDs, and a tendency to recur. However, unlike other autoimmune diseases, circulating anti-heart antibodies are detected within 14 days of PCIS rather than at the time of diagnosis [18], and therefore do not help in PCIS diagnosis.

Both of our patients were treated with corticosteroids instead of NSAIDs, since NSAIDS were contraindicated in both patients. However, aspirin, NSAID, steroid, and colchicine have been reported as the main treatment options in a number of current case reports describing pacemaker- or PCI-induced PCIS [8, 19], and the dosage and duration of treatment are presented in Table $1[20,21]$. Corticosteroids are usually considered as second-line treatment for patients who show a poor response to NSAIDS, or when NSAID use is contraindicated due to higher adverse event rates, longer disease duration, and higher recurrence rate $[6,20,21]$. When patients are symptom-free and exhibit normalized levels of inflammatory markers, a slow taperingdown of the steroid is recommended rather than an accelerated decrease [21]. In our case 1, the patient was administered colchicine after he had recurrent PCIS. Some case reports described simultaneous administration of colchicine along with NSAIDs or corticosteroid from the beginning, since colchicine has proved to be useful in treating refractory or recurrent post- pericardiotomy syndrome, and in lowering the recurrence rate [22]. However, if the patient does not respond to second-line treatment with steroid plus colchicine, then a combination of NSAIDs, steroids and colchicine should be considered as the next treatment option [21]. There is also one recent reported PCIS case rapidly occurred after pacemaker implantation, which was solved by prednisolone and colchicine successfully [23].

PCIS can have a good prognosis, and patients with PCIS can be treated conservatively using NSAIDs, steroids, and colchicine. Diagnosis of PCIS is usually based on exclusion of other possible causes of pericarditis.

\begin{abstract}
Abbreviations
CXR: Chest X radiography; CT: Computed tomography; ECG: Electrocardiography; HU: Hounsfield unit; PCI: Percutaneous coronary intervention; PCIS: Post cardiac injury syndrome; RCA: Right coronary artery; RV: Right ventricle.
\end{abstract}

\section{Acknowledgements}

Not applicable.

\section{Authors' contributions}

MSH and YHS created initial drafts of the manuscript. JYC did the surgery. JYC advised edits of the final manuscript. All authors have read and approved the manuscript.

\section{Funding}

The authors would like to thank the support for the study from the Ministry of Science and Technology of the Republic of China, Taiwan for financial support of this research under contract MOST 110-2218-E-006-017.

Availability of data and materials

Not applicable.

\section{Declarations}

Ethics approval and consent to participate

Not applicable.

\section{Consent for publication}

Written consent to publish this information was obtained from study participants.

\section{Competing interests}

All authors confirm that they have no competing interests.

\section{Author details}

'Division of Cardiology, Department of Internal Medicine, National Cheng Kung University Hospital, College of Medicine, National Cheng Kung University, 138 Sheng-Li Road, Tainan 704, Taiwan. ${ }^{2}$ Post Graduate Residency Program, Education Center, Department of Neurosurgery, National Cheng Kung University Hospital, Taipei Veteran General Hospital, Taipei City, Taiwan.

Received: 17 June 2021 Accepted: 9 August 2021

Published online: 14 August 2021

Table 1 Suggested medication and dosage for post cardiac injury syndrome

\begin{tabular}{lll}
\hline Medication & Dosage & Duration \\
\hline Ibuprofen & $600 \mathrm{mg} \mathrm{tid}$ & $1-2$ weeks for acute case, and 2-4 weeks for recurrent cases \\
Indomethacin & $25-50 \mathrm{mg} \mathrm{tid}$ & \\
Aspirin & $750-1000 \mathrm{mg}$ tid & $2-4$ weeks of treatment before slow tapering off \\
Corticosteroid & $0.2-0.5 \mathrm{mg} / \mathrm{kg}$ per day & 3 months for acute PCIS, 6 months for recurrent PCIS \\
Colchicine & BW $>70 \mathrm{kg:}: 0.5 \mathrm{mg}$ bid & \\
& BW $<70 \mathrm{~kg}: 0.5 \mathrm{mg} \mathrm{qd}$ & \\
\hline
\end{tabular}




\section{References}

1. Imazio M, Hoit BD. Post-cardiac injury syndromes: an emerging cause of pericardial diseases. Int J Cardiol. 2013;168:648-52.

2. Bielsa S, Corral E, Bagüeste P, Porcel JM. Characteristics of pleural effusions in acute idiopathic pericarditis and post-cardiac injury syndrome. Ann Am Thorac Soc. 2016;13:298-300.

3. Levy Y, Shovman O, Granit C, Luria D, Gurevitz O, Bar-Lev D, Eldar M, Shoenfeld Y, Glikson M. Pericarditis following permanent pacemaker insertion. Isr Med Assoc J. 2004:6:599-602.

4. Zeltser I, Rhodes LA, Tanel RE, Vetter VL, Gaynor JW, Spray TL, Cohen MI. Postpericardiotomy syndrome after permanent pacemaker implantation in children and young adults. Ann Thorac Surg 78:1684-1687.

5. Troughton RW, Asher CR, Klein AL. Pericarditis. Lancet. 2004;363:717-27.

6. Lazaros G, Sideris S, Antonopoulos A, Oikonomou E, Milkas A, Archontakis S, Tolis P, Latsios G, Papaioannou S, Kallikazaros I, Tousoulis D. Incessant pericarditis following dual-chamber cardioverter defibrillation device implantation. Int J Cardio/ 212:184-186.

7. Hearne C, Forjuoh SN. Postcardiac injury syndrome after coronary angioplasty and stenting. J Am Board Fam Pract. 2003;16:73-4.

8. Sedaghat-Hamedani F, Zitron E, Kayvanpour E, Lorenz HM, Katus HA, Meder B. Post cardiac injury syndrome after initially uncomplicated CRT-D implantation: a case report and a systematic review. Clin Res Cardiol. 2014;103:781-9.

9. Ohlow M, Lauer B, Brunelli M, Geller JC. Incidence and predictors of pericardial effusion after permanent heart rhythm device implantation prospective evaluation of 968 consecutive patients. Circ J. 2013;77:975-81.

10. Setoyama T, Furukawa Y, Abe M, Nakagawa Y, Kita T, Kimura T. Acute pleuropericarditis after coronary stenting: a case report. Circ J. 2006;70:358-61.

11. Hearne C, Forjuoh SN. Postcardiac injury syndrome after coronary angioplasty and stenting. J Am Board Fam Med. 2003;16:73-4.

12. Rakhshan E, Mirabbasi SA, Khalighi B, Khalighi K. Pericarditis-induced hyponatremia after cardiac electronic implantable device (CEID) procedures. Am J Case Rep. 2015;16:245-9.

13. Groves PH, Shah AM, Hutchison SJ. Hyponatraemia secondary to an inappropriately high release of antidiuretic hormone in cardiac tamponade. $\mathrm{Br}$ Heart J. 1990;64:206-7.
14. Chang FK, Lee YC, Chiu CH. Hyponatremia in patients with symptomatic pericardial effusion. J Chin Med Assoc. 2012;75:509-12.

15. Mahapatra S, Bybee KA, Bunch TJ, Espinosa RE, Sinak LJ, McGoon MD, et al. Incidence and predictors of cardiac perforation after permanent pacemaker placement. Heart Rhythm. 2005;2:907-11.

16. Greene TO, Portnow AS, Huang SK. Acute pericarditis resulting from an endocardial active fixation screw-in atrial lead. Pacing Clin Electrophysiol. $1994 ; 17: 21-5$.

17. Sivakumaran S, Irwin ME, Gulamhusein SS, Senaratne MP. Postpacemaker implant pericarditis: incidence and outcomes with active-fixation leads. Pacing Clin Electrophysiol. 2002;25:833-7.

18. Hoffman M, Fried M, Jabareen F, Vardinon N, Turner D, Burke M, et al. Anti-heart antibodies in postpericardiotomy syndrome: cause or epiphenomenon? A prospective, longitudinal pilot study. Autoimmunity. 2002;35:241-5.

19. Tsai WC, Liou CT, Cheng CC, Tsai KS, Cheng SM, Lin WS. Post-cardiac injury syndrome after permanent pacemaker implantation. Acta Cardiol Sin. 2012;28:53-5.

20. Imazio M, Gaita F, LeWinter M. Evaluation and treatment of pericarditis: a systematic review. JAMA. 2015;314:1498-506.

21. Imazio M, Lazaros G, Brucato A, Gaita F. Recurrent pericarditis: new and emerging therapeutic options. Nat Rev Cardiol. 2013;13:99-105.

22. Lotrionte M, Biondi-Zoccai G, Imazio M, Castagno D, Moretti C, Abbate A, Agostoni P, Brucato AL, Di Pasquale P, Raatikka M, Sangiorgi G, Laudito A, Sheiban I, Gaita F. International collaborative systematic review of controlled clinical trials on pharmacologic treatments for acute pericarditis and its recurrences. Am Heart J. 2010;160:662-70.

23. Chlabicz M, Jakim P, Zalewska-Adamiec M, Róg-Makal M, Dobrzycki S. (2021) A rare case of acute pleuropericarditis as a complication of permanent pacemaker insertion. Am J Case Rep. 22:e928188.

\section{Publisher's Note}

Springer Nature remains neutral with regard to jurisdictional claims in published maps and institutional affiliations.
Ready to submit your research? Choose BMC and benefit from:

- fast, convenient online submission

- thorough peer review by experienced researchers in your field

- rapid publication on acceptance

- support for research data, including large and complex data types

- gold Open Access which fosters wider collaboration and increased citations

- maximum visibility for your research: over $100 \mathrm{M}$ website views per year

At BMC, research is always in progress.

Learn more biomedcentral.com/submissions 